Hope College

Hope College Digital Commons

Faculty Publications

$1-2008$

\title{
Retributive Justice, Restorative Justice, And Forgiveness: An Experimental Psychophysiology Analysis
}

\author{
Charlotte vanOyen-Witvliet \\ Hope College,witvliet@hope.edu \\ Everett L. Worthington \\ Virginia Commonwealth University \\ Lindsey M. Root \\ University of Miami \\ Amy F. Sato \\ University of Wisconsin - Milwaukee \\ Thomas E. Ludwig \\ Hope College, ludwig@hope.edu
}

See next page for additional authors

Follow this and additional works at: https://digitalcommons.hope.edu/faculty_publications

Part of the Psychology Commons

\section{Recommended Citation}

Witvliet, Charlotte V. O., Everett L. Worthington, Lindsey M. Root, Amy F. Sato, Thomas E. Ludwig, and Julie J. Exline. "Retributive Justice, Restorative Justice, and Forgiveness: An Experimental Psychophysiology Analysis." Journal of Experimental Social Psychology 44, no. 1 (January 2008): 10-25. doi:10.1016/ j.jesp.2007.01.009.

This Article is brought to you for free and open access by Hope College Digital Commons. It has been accepted for inclusion in Faculty Publications by an authorized administrator of Hope College Digital Commons. For more information, please contact digitalcommons@hope.edu. 


\section{Authors}

Charlotte vanOyen-Witvliet, Everett L. Worthington, Lindsey M. Root, Amy F. Sato, Thomas E. Ludwig, and Julie J. Exline 
Running Head: RETRIBUTIVE JUSTICE, RESTORATIVE JUSTICE, AND FORGIVENESS

Witvliet, C.V.O., Worthington, E.L., Jr., Root, L.M., Sato, A.F., Ludwig, T.E., \& Exline, J.J. (2008). Retributive justice, restorative justice, and forgiveness: An experimental psychophysiology analysis. Journal of Experimental Social Psychology y, 44, 10-25.

Retributive Justice, Restorative Justice, and Forgiveness:

An Experimental Psychophysiology Analysis

\author{
Charlotte V.O. Witvliet \\ Hope College \\ Everett L. Worthington \\ Virginia Commonwealth University \\ Lindsey M. Root \\ University of Miami (Hope graduate) \\ Amy F. Sato \\ University of Wisconsin-Milwaukee (Hope graduate) \\ Thomas E. Ludwig \\ Hope College \\ Julie J. Exline \\ Case Western Reserve University
}

\footnotetext{
Please direct correspondence to Charlotte vanOyen Witvliet, Ph.D., Psychology Department, Hope College, Holland, MI 49422-9000; email: witvliet@hope.edu. We gratefully acknowledge the support offered through the first author's Towsley Research Scholar award and an internal grant from Hope College.
} 


\begin{abstract}
This experiment assessed the emotional self-reports and physiology of justice outcomes and forgiveness responses to a common crime, using a 3 Justice (retributive, restorative, no justice) x 2 Forgiveness (forgiveness, none) repeated measures design. Participants (27 males, 29 females) imagined their residence was burglarized, followed by six counterbalanced justice-forgiveness outcomes. Imagery of justice—especially restorative—and forgiveness each reduced unforgiving motivations and negative emotion (anger, fear), and increased prosocial and positive emotion (empathy, gratitude). Imagery of granting forgiveness (versus not) was associated with less heart rate reactivity and better recovery; less negative emotion expression at the brow (corrugator EMG); and less aroused expression at the eye (lower orbicularis oculi EMG when justice was absent). When forgiveness was not imagined, justice-physiology effects emerged: signs of cardiovascular stress (rate pressure products) were lower for retributive versus no justice; and sympathetic nervous system responding (skin conductance) was calmer for restorative versus retributive justice.
\end{abstract}

KEY WORDS: retributive justice, restorative justice, forgiveness, emotion, physiology, stress 150 words 
Retributive Justice, Restorative Justice, and Forgiveness:

An Experimental Psychophysiology Analysis

Interpersonal offenses foster perceptions of injustice. What difference might it make for victims if they see offenders brought to justice through punishment or restorative justice? What effects might occur if victims do or do not forgive their offenders? The interface of justice and forgiveness has emerged as an important topic for psychological study (e.g., Armour \& Umbreit, 2005; Exline, Worthington, Hill, \& McCullough, 2003; Hill, Exline, \& Cohen, 2005), with Karremans and Van Lange (2005) initiating experimental research in this area. The current work targets these issues using an experimental psychophysiological approach that assesses the victim's subjective and physiological responses for various imagined justice outcomes both with and without imagining one's forgiveness of the offender.

\section{Injustice and Unforgiveness}

When an offense occurs, victims typically feel a discrepancy between the way things currently are and how they ought to be. In the wake of such a serious and intentional offense as a burglary, a victim might desire retributive justice, which focuses on punishing the offender (for reviews, see Darley, 2002; Darley \& Pittman, 2003; Tyler, Boeckman, Smith, \& Huo, 1997; Vidmar, 2002). Another option is restorative justice in which the offender is held accountable and the victim may receive compensation or conciliatory behaviors such as expressions of remorse by the offender (for reviews, see Armour \& Umbreit, 2005, Bazemore, 1998; Braithwaite, 1989; Cohen, 2001; Umbreit, 2001; Zehr, 1995). In the absence of such justice outcomes, victims are likely to experience what Worthington (2006) termed an injustice gap — a discrepancy between the desired level of justice and the actual level of justice. The size of the gap can change with time, widening in the case of additional perceived injustices (e.g., if the offender is acquitted due to a technicality), and narrowing as acts of justice occur (e.g., with an offender's conviction and appropriate sentencing, or with a satisfying Victim Offender Mediation experience).

An injustice gap is not merely a cognitive judgment about the disparity between the current situation and the desired outcome; it is also charged with negative emotions (Worthington \& Scherer, 2004). Anger and other negative emotions that attend a perceived injustice may coalesce over time in 
emotional unforgiveness (Worthington \& Wade, 1999) proportional to the size of the injustice gap (Worthington \& Scherer, 2004). Emotional unforgiveness is not the polar opposite of forgiveness, as the terms might suggest. Rather, people can reduce the resentment, anger, and fear of unforgiveness (and narrow the injustice gap) in many ways other than forgiveness. For example, they might pursue justice, excuse or minimize the offense, or simply accept the events and move on (Wade \& Worthington, 2002).

\section{Forgiveness Defined}

Forgiveness differs from condoning, excusing, tolerating, minimizing (Enright \& Fitzgibbons, 2000), or forbearing (McCullough, Fincham \& Tsang, 2003), which are alternative ways to reduce unforgiveness. Forgiveness is also different from reconciling (cf. Freedman, 1998; Worthington \& Drinkard, 2000), which involves restoring trust. Rather, forgiveness partially or totally eclipses unforgiving motivations (e.g., revenge and/or avoidance) and emotions (e.g., fear, sadness, and/or anger) by fostering positive thoughts (e.g., focusing on the offender's humanity rather than defining him or her in terms of the offense) and emotions (e.g., compassion, empathy, mercy) toward the offender. We work with a multidimensional definition of forgiveness, noting its cognitive (Enright \& Fitzgibbons, 2000), emotional (Witvliet, Ludwig, \& Vander Laan, 2001; Worthington, 2006), motivational (McCullough et al., 2003), and social features (Finkel, Rusbult, Kumashiro, \& Hannon, 2002). We view the verbalcognitive, physiological, and behavioral changes that occur with forgiveness as constitutive elements of emotional forgiveness (Worthington \& Wade, 1999), resonating with Lang's (1995) bioinformational theory of emotion.

\section{Justice and Forgiveness: Proposed Implications for Emotion, Stress, and Health}

Recent reviews have assessed relationships among unforgiveness, forgiveness, and health (Harris \& Thoresen, 2005; Worthington \& Scherer, 2004). In setting a research agenda, Worthington and Scherer (2004) offered four testable propositions that the current experiment addresses. First, unforgiveness is stressful. Second, a variety of coping mechanisms can reduce unforgiveness. For example, one could take the problem-focused approach of seeking to establish justice. If this were effective, it would narrow the theoretical injustice gap and thereby reduce the stress of unforgiveness. Third, emotion-focused coping 
via granting forgiveness can reduce the stress of unforgiveness. Fourth, because stress is linked to health, forgiveness is likely also related to health. Worthington and Scherer (2004) view forgiveness as an emotion-focused coping strategy that is associated with calmer physiological reactivity and recovery patterns than unforgiveness (Lawler et al., 2003; Witvliet et al., 2001).

In their agenda for justice and forgiveness research, Exline et al. (2003) note that the U.S. legal system has focused primarily on retributive justice. In retributive contexts, little interaction occurs between offenders and victims, and minimal attention is paid to the needs of victims. The restorative justice movement, by contrast, has increased attention to the rights and dignity of victims as well as offenders (Armour \& Umbreit, 2005; Bazemore, 1998; Braithwaite,1989; Cohen, 2001; Umbreit, 2001; Zehr, 1995). As detailed by Umbreit (2001), restorative justice approaches can involve supervised meetings between offenders and victims. In this context, offenders can hear the victim's story, offer accounts (e.g., explanations, apologies), and determine appropriate restitution. Importantly, restorative justice does not explicitly promote forgiveness. If forgiveness emerges, it is because victims initiate it.

While common sense suggests that justice—whether retributive or restorative—brings a sense of closure to victims (i.e., narrowing the injustice gap), this has not been studied experimentally. How might we study the effects of the absence of justice, retributive, and restorative justice, especially if we are interested in intersections with forgiveness? Victim-offender mediation meetings are difficult to investigate in vivo. First, the meetings are often protected by law. Second, stringent standards for consent are needed because prisoners are vulnerable to coercion. Third, within the community that advocates victim-offender meetings, victim advocates often desire to protect their clients from pressures to forgive (see Armour \& Umbreit, 2005). Fourth, even if such meetings were available to research, the intrusiveness of videotaping, administering questionnaires, and/or monitoring physiological responses could prevent an accurate understanding of the naturalistic processes experienced by participants.

Another means of investigating justice and forgiveness is needed. The U.S. Department of Justice Federal Bureau of Investigation (2006) documented that 10.16 million property crimes were reported in the previous year, including 2.15 million burglaries, $62 \%$ of which were daytime residential burglaries. 
For property crimes, restorative justice methods are being applied with increasing frequency (Armour \& Umbreit, 2005). From a research perspective, crime is a clear one-sided transgression—unlike a betrayal in an ongoing relationship where both parties may share some blame. Thus, the study of crimes and their aftermath provides an ideal social psychological situation in which to justice and forgiveness.

We have developed an experimental paradigm that enables moment-by-moment physiological and subjective assessment in the laboratory. Whereas such assessments have limited generalizability to actual victim-offender meetings, they have strong internal validity. They also enable comparisons with other psychophysiological experiments that have assessed granting forgiveness (Lawler et al., 2003; Witvliet et al., 2001), seeking forgiveness, (Witvliet, Ludwig, \& Bauer, 2002), and the effects of apology and restitution (Witvliet, Worthington, \& Wade, 2002).

\section{Assessing Justice and Forgiveness as Independent Variables}

A foundation for experimental research on forgiveness and justice was established by Karremans and Van Lange (2005), who found that priming justice values increased participants' self-reported forgiveness responses. They found that most participants spontaneously conceptualized justice as prosocial value, which may have altered their propensity to forgive. Participants who wrote about justice in retributive ways tended to have lower forgiveness scores than those who did not (Karremans \& Van Lange, 2005, footnote 3). Retributive and prosocial (e.g., restorative) justice values may carry different implications for forgiveness, which is one of the hypotheses that we investigated in the current study.

We designed an experimental study to test the effects of justice (i.e., comparing a lack of justice, retributive justice, and restorative justice) and its interaction with forgiveness (i.e., comparing a lack of forgiveness to granting of forgiveness). We tested their effects on self-reported motives and emotions as well as physiological responses related to emotion and stress. We appropriated a methodology from emotion research on how the two dimensions of emotional valence (negative to positive) and arousal Low to high) are associated with differing physiological response patterns (see Witvliet \& Vrana, 1995), in research on forgiveness and unforgiveness (see Witvliet et al., 2001), and in research on apology and restitution (see Witvliet, Worthington, \& Wade, 2002). 
Our purpose in this paper is not to advocate for a particular model of justice or to prescribe forgiveness (following suggestions by Armour \& Umbreit, 2005). Rather, we see justice and forgiveness as possibly complementary approaches that may be pursued independently or together.

\section{Hypothesized Justice Effects}

In terms of justice, we hypothesized that compared to the absence of justice, both retributive and restorative justice would be more effective at reducing unforgiveness (presumably by narrowing the injustice gap). But how might retributive and restorative justice compare? Given research on apology and restitution (Witvliet, Worthington, \& Wade, 2002), we predicted that restorative justice would be effective in reducing unforgiving motivations and emotions, prompting positive and prosocial emotion, and decreasing physiological responses associated with negative and arousing emotion. Such a finding would be consistent with prior work suggesting that apologies and concessions facilitate forgiveness (see Exline et al., 2003, for an overview). Furthermore, in the justice scripts of the current study, the victim imagined waiting weeks and months for the justice outcome, and then-in the restorative justice condition — the offender expressed remorse. Frantz and Bennigson (2005) found that this passage of time may make recipients of an apology more "ripe” to receive it, thereby resulting in greater satisfaction with a delayed apology. Of note, however, apologies (Brown, 2005) as well as responsibility-taking accounts (Hodgins \& Liebeskind, 2003) tend to be more effective when offered within more intimate rather than distal relationships such as the crime perpetrator-victim context studied here.

Because punishment of offenders meets justice demands, this outcome should help to reduce the injustice gap, and hence unforgiveness. Victims may believe that seeing offenders punished will bring satisfaction and relief. However, retributive justice approaches focus only on the issue of just deserts for offenders; they do not try to compensate offended parties or to help meet their emotional needs. Retributive approaches are also unlikely to directly promote prosocial responses or reconciliation. We therefore predicted that in terms of reducing unforgiveness and physiological indicators of negative and aroused emotion, retributive justice would be more effective than no justice, but less effective than restorative justice. 


\section{Hypothesized Forgiveness Effects}

Compared to not granting forgiveness, we hypothesized that imagery of granting forgiveness would be associated with lower unforgiving motivations and emotions, higher positive emotions and prosocial responses, and less physiological reactivity associated with negative and arousing emotion. Victims have already been found to benefit from taking a forgiving stance toward their real-life offenders. Using a within-subjects mental imagery design, Witvliet et al. (2001) found that when people imagined unforgiveness—ruminating about their hurt and nursing a grudge - they experienced more negative and aroused emotion, higher heart rate, blood pressure, and skin conductance levels, and greater muscle tension above the brow (corrugator EMG) and under the eye (orbicularis oculi EMG). When these same people instead imagined forgiving responses_cultivating empathy and focusing on prosocial responses to the offender-they experienced more positive emotion, more perceived control, and comparatively less physiological reactivity with better heart rate and brow tension recovery responses. In a complementary study in which participants were interviewed about prior experiences with conflict, Lawler et al. (2003) found patterns of reduced cardiovascular reactivity and better recovery patterns for trait and state forgiving. Collectively, these studies suggest that chronic unforgiving responses could contribute to adverse health by perpetuating stress, sympathetic nervous system arousal, heightened cardiovascular reactivity, and impaired cardiovascular recovery, whereas forgiving responses may buffer health by quelling these responses. The present study enabled us to examine whether victims may accrue forgiveness benefits from imagery of granting forgiveness regardless of the justice outcome.

\section{Justice and Forgiveness Comparisons}

Crime victims often look to justice outcomes to bring closure, and thereby reduce their negative emotions and restore more positive and calm emotion. We tested the effects of retributive and restorative justice versus the effects of forgiveness. Restorative justice can include elements of remorse and restitution that facilitate forgiveness and calm physiological reactivity (Witvliet, Worthington, \& Wade, 2002). Hence, we predicted that the dependent variables in the restorative-justice-only and forgivenessonly scenarios would not differ. However, we hypothesized that forgiveness-only and restitution-only 
imagery would be associated with less negative and stress-related responses, and with more positive outcomes than the retributive-justice-only imagery condition. This is because retributive justice primarily punishes the offender, but does not directly attend to the emotional needs of the victim. Karremans and Van Lange (2005) found that when participants focused on retributive justice, they tended not to be as forgiving as those with a prosocial perspective of justice. Although retributive justice may reduce the injustice gap, we predicted that it would not have as strong of an effect on a victim's emotional responses as would the more personal experiences of restorative justice and granting forgiveness.

\section{Psychophysiological Responses and Study Goals}

To evaluate whether justice and forgiveness factors influence unforgiveness, we measured revenge and avoidance motivations as well as anger, fear, and sadness. To assess the presence of positive prosocial emotion, we measured gratitude as well as empathy and forgiveness. Measuring forgiveness serves as a manipulation check and also enables us to assess whether different justice outcomes modulate participants' experiences of forgiving. To determine how justice and forgiveness outcomes influence the emotional dimensions, participants rated emotional valence (ranging from negative to positive), arousal, and perceived control. By measuring this set of dependent variables, findings could be compared to those from other psychophysiological experiments (Witvliet et al. 2001; Witvliet, Worthington, \& Wade, 2002).

Finally, we measured physiological responses that have been explicitly tied to emotional valence and arousal (Witvliet \& Vrana, 1995). Specifically, we measured EMG at the brow (corrugator) because activity there is accentuated during negative imagery. We also measured heart rate, skin conductance, and EMG under the eye (orbicularis oculi), because these measures are responsive to arousal levels during imagery. We also assessed rate pressure product scores (the product of heart rate and systolic blood pressure), which reflect myocardial oxygen demand and indicate stress (Lawler et al., 2003). Hypotheses

We used these self-report and physiological measures in an imagery study using crime outcome and response scenarios to test the following hypotheses (per Worthington \& Scherer, 2004): 
(a) the unforgiveness condition (i.e., the no-justice-or-forgiveness condition) would be associated with higher stress than the other conditions. This would be indicated by higher negative and aroused emotion reports and elevated physiology levels on the measures sensitive to valence and arousal;

(b) the retributive and/or restorative justice conditions would have lower unforgiveness and higher positive prosocial emotion levels than the no-justice conditions;

(c) retributive and/or restorative justice conditions would also be associated with lower physiological indicators of stressful (i.e., high arousal and negatively valent) emotion compared to the nojustice conditions,

(d) the granting forgiveness conditions would have lower unforgiveness and higher positive prosocial emotions levels than the no-forgiveness conditions;

(e) the granting forgiveness condition would be associated with lower physiological indicators of stressful (i.e., high arousal and negatively valent) emotion, than the no-forgiveness conditions; and

(f) the forgiveness-only condition would have significantly lower negative emotions, stressrelated physiology, and higher positive prosocial emotions than the retributive-justice-only condition, but would not differ from the restorative-justice-only condition.

Method

\section{Participants}

Introductory psychology students ( $N=56 ; 27$ males, 29 females) participated to satisfy a research requirement. All participants were 18 years or older $(M=19.0$ years, $S D=1.0)$. Of the 56 participants, 51 were White, 2 Asian-American, 1 African-American, and 1 Latino. All reported that they could imagine the burglary scenario actually happening to them $(M=4.18, S D=.87$, range $=1$ a little -6 extremely $)$. Of the participants, 32 percent reported that the burglary scenario reminded them of a situation in their lives, and 23 percent reported having been personally robbed or burglarized prior to the study. 


\section{Stimulus Materials}

Participants read a burglary scenario that (a) parallels the example Exline et al. (2003) employed to illustrate an injustice gap, (b) corresponds to a case example used by Umbreit (2001) to illustrate victimoffender mediation, and (c) extends research on apology and restitution after crime (Witvliet, Worthington, \& Wade, 2002). They then read and imagined experiencing all six outcome scenarios (see Appendix). To maximize external validity, justice scripts were developed in consultation with a legal professional. The no-justice-no-forgiveness script focused on features of the injustice gap and illustrated a common victim response,; the retributive and restorative justice scripts mirrored realistic outcomes in the state in which the study was conducted. The three justice scenarios that encouraged a forgiveness response adapted materials from Witvliet et al. (2001). The forgiveness description incorporated elements of granting forgiveness, including empathy (see McCullough, Worthington, \& Rachal, 1997) and other prosocial responses (e.g., Worthington \& Scherer, 2004; Worthington \& Wade,1999).

\section{Dependent Measures}

\section{Questionnaires}

Transgression-Related Interpersonal Motivations Inventory (TRIM; McCullough et al., 1998). Unforgiving motivations were measured using the TRIM. Five items measured the motivation to seek revenge (e.g., "I want to see him/her hurt and miserable”). Seven items measured the motivation to avoid the offender (e.g., “I do not trust him/her”). Participants rated items on a 5-point Likert-type scale (1 = strongly disagree to 5 = strongly agree). Estimated internal consistency for the TRIM is high (Cronbach's alphas .86 to .94), moderate test-retest stability (3-week test-retest $r \mathrm{~s}=.79-.86$, 8-week test-retest $r \mathrm{~s}=$ $.44-.53$, 9-week test retest $r s=.64-.65$ ), and evidence of construct validity (McCullough et al., 1998). Cronbach’s alphas in our research have ranged from .81 to .93 (Witvliet, Worthington, \& Wade, 2002).

Empathy Adjectives (Batson, Bolen, Cross, \& Neuringer-Benfiel, 1986). Prosocial feelings were measured with Batson’s 8-item Empathy Scale. Participants rated eight words—sympathetic, empathic, concerned, moved, compassionate, softhearted, warm, and tender-using a six-point scale (ranging from 
$1=$ Not at all to $6=$ Extremely). In our research, Cronbach's alpha estimates of internal reliability for this scale have ranged from .82 to .93 (Witvliet, Worthington, \& Wade, 2002).

Scale of Forgiveness as Positive Responses to an Offender (PRO). The PRO is an inventory that measures the likelihood of positive feelings, behaviors, and thoughts toward an offender. Six items are rated on a five-point scale from Not at all likely (1) to Extremely likely (5). Items include (1) Think positive thoughts about her/him, (2) Help her/him out if in difficulty, (3) Want the best for him/her, (4) Understand the motivation for her/his actions toward me, (5) Give him/her the benefit of the doubt regarding this offense, and (6) Feel positive emotions toward him/her. During scale development by Witvliet, Worthington, and Wade (2002), Cronbach’s alphas were .85 at pre-test and .88 at post-test, exploratory factor analysis indicated that the six items measured one construct (Eigenvalue of 3.76, accounting for $63 \%$ of the item variance), and all items had factor loadings over .75 .

Physiology ${ }^{1}$

As participants imagined the six justice-forgiveness outcomes in Section II, we continuously measured heart rate, blood pressure, skin conductance levels, and facial electromyographic activity (EMG) at the corrugator (brow) and orbicularis oculi (under the eye) muscle regions. Heart rate and blood pressure were monitored on a heartbeat-to-heartbeat basis, and facial EMG and skin conductance were monitored on a second-to-second basis. Cardiac interbeat intervals were converted to heart rate in beats per minute for each imagery period. Blood pressure was measured continuously and non-invasively (see footnote 1). In addition to measuring systolic, diastolic, and mean arterial pressure, we calculated rate pressure product, the product of heart rate and systolic blood pressure, which is an indicator of myocardial oxygen demand and stress (e.g., Kitamura, Jorgensen, Gebel, \& Wang, 1972).

\section{Ratings}

To rate subjective emotions associated with each type of imagery, participants used a video display and computer joystick (see Hodes, Cook, \& Lang, 1985 for a description of all ratings used). Participants rated their emotional valence (negative-positive), arousal (low-high), and perceived control (low-high) by manipulating an image of an androgynous figure so that it exhibited emotional expressions 
consistent with their own experience. Participants also rated imagery vividness by manipulating an image of a cube, from completely fragmented to clear and vivid. In addition, participants used a joystick to manipulate a cursor along a continuum to rate how much they had felt gratitude, fear, and anger (anchored by Not at All on the left, Moderately in the middle, and Completely on the right). All ratings were converted to a scale ranging from 0 to 20 using VPM software (Cook et al., 1987), as in other studies (Witvliet \& Vrana, 1995, 2000; Witvliet et al., 2001; Witvliet, Worthington, \& Wade, 2002). Participants privately registered all ratings directly into a computer, were told there were no right or wrong answers, and were encouraged to be completely honest.

\section{Procedure}

Each participant completed an individual two-hour session consisting of two sections. In Section I, participants read a scenario describing the burglary of his or her residence. Then, to assess initial responses to the crime, participants completed questionnaires that assessed unforgiveness motivations (i.e., the TRIM), empathy (i.e., Batson’s Empathy Adjectives), and forgiveness (i.e., the PRO). Subsequently, participants read the six possible justice-forgiveness outcome scenarios—counterbalanced across participants using a Latin Square design (See Appendix Table 1). After imagining each outcome scenario, participants again completed the unforgiveness, empathy, and forgiveness questionnaires.

In Section II, the participant entered a room with a recliner chair, computer, and electrodes and again imagined the six outcome scenarios. But in this section, participants imagined each of the six scenarios four times, for a total of 24 imagery trials. The order of imagery trials was systematically manipulated across participants using a Latin Square design (See Appendix Table 2).

Section II was divided into three separate blocks of eight trials. In each block, each of the participants imagined one of the scenario outcomes whenever a high-pitched tone occurred, and a different type of scenario outcome whenever a low-pitched tone occurred. There were four high-tone and four low-tone imagery trials in each block. A medium-pitched tone signaled the participant to engage in a relaxation task, thinking the word “one” every time he or she exhaled (e.g., Witvliet \& Vrana, 1995, 2000). A variable number of medium-tone relaxation periods separated the imagery trials, and high-tones 
and low-tones occurred in a quasi-random order so that participants were unsure of when the next imagery period would begin, and what type of imagery they would imagine next. Each trial consisted of an 8-s baseline (relaxation) period, 16-s imagery period, and 8-s recovery (relaxation) period. Between trials were 16-32 seconds of relaxation. Physiological responses were measured continuously during each trial's baseline, imagery, and recovery periods, enabling measurement of the immediate psychophysiological effects of participants’ responses as they occurred.

Following a block of trials, a long high tone cued participants to rate their high-tone-cued imagery. Then a long low tone signaled participants to rate their low-tone-cued imagery. Participants used a joystick and computer to privately register their ratings.

\section{Statistical Analyses}

For this repeated-measures design in which three levels of justice (no justice, retributive justice, and restorative justice) were crossed with two levels of forgiveness,, we conducted 3 x 2 (Justice x Forgiveness) repeated-measures ANOVAs on the ratings and physiological scores. We interpreted the results using the multivariate tests because they do not assume sphericity (cf. Green, Salkind, \& Akey, 2000). For each dependent variable, we report the Wilks’ Lambda $F$ statistic equivalent for the justice main effect, forgiveness main effect, and Justice x Forgiveness interaction. Means and ANOVA statistics for the self-report and physiology data appear in Table 1 and Figure 1, respectively.

When a significant justice main effect occurred, we averaged the data within each of the three justice levels to form no justice, retributive justice, and restorative justice variables. We then conducted three follow-up pairwise $t$-tests (two-tailed) as follows: no justice versus retributive justice, no justice versus restorative justice, and retributive versus restorative justice. We controlled for the Type I error rate by using a corrected $p$ value of $.05 / 3=.017 .^{2}$ Only significant effects are reported.

When a significant Justice x Forgiveness interaction occurred, we used two approaches so that we could address both justice and forgiveness hypotheses. First, we analyzed justice effects at each level of forgiveness (imagined versus not). We then analyzed forgiveness effects at each level of justice (none, retributive, restorative). Although this is redundant statistically, this strategy makes interpretations clear. 
Finally, because of theoretical interests, we analyzed the effects of forgiveness-only in comparison to retributive-justice-only and restorative-justice-only. Hence, we conducted eleven planned pairwise $t$-tests (two-tailed) with the adjusted alpha of .05/11 =.0045 to control for the risk of an inflated Type I error rate. To clearly communicate the results of these analyses, we document the significance of these contrasts in Table 1, and we describe in the Results section those differences that met this stringent criterion.

Results

Self-Report Data

All self-report means and statistical effects are reported in Table 1.

\section{Unforgiving Motivations (TRIM) and Emotions (Anger and Fear)}

TRIM and anger scores both showed a significant Justice x Forgiveness interaction. Justice effects were apparent in the absence of imagining forgiveness: unforgiving motivations and anger ratings systematically decreased across the justice levels, from no justice to retributive justice to restorative justice. By contrast, when forgiveness was imagined, it seemed to mute the justice effects: only restorative justice subdued anger compared to no justice (see Table 1). Forgiveness had an effect regardless of justice outcome, always yielding lower unforgiving motivations and anger. Finally, analyses showed that forgiveness-only reduced unforgiving motivations and anger compared to retributive-justiceonly, but was statistically equivalent to restorative-justice-only.

Fear ratings showed main effects of justice and forgiveness. Whereas retributive and restorative justice were statistically equivalent, each was associated with less fear than the no justice condition. Imagining forgiveness was associated with less fear than not imagining forgiveness.

\section{Empathy, Positive Responses, and Gratitude}

Because research shows that forgiveness is not the only means of reducing unforgiveness (Wade \& Worthington, 2002), it is important in forgiveness studies to determine whether victims experience 
empathy, positive responses (e.g., emotions, cognitions, and behaviors), and facilitative emotions (e.g., gratitude). Significant Justice x Forgiveness interactions occurred for all of these measures.

In the absence of forgiveness, empathy systematically increased across the no justice, retributive justice, and restorative justice conditions. However, with imagined forgiveness, empathy levels were similar across the justice conditions, suggesting that the forgiveness imagery carried a sense of empathy for the offender. Regardless of justice outcome, forgiveness imagery was associated with greater empathy. Finally, imagery of granting forgiveness-only increased empathy (and decreased TRIM and anger ratings) compared to imagery of retributive-justice-only, but did not differ from restorative-justiceonly.

The PRO measure of prosocial emotions, actions, and cognitions served as a manipulation check of the forgiveness imagery. It confirmed that when participants were asked to imagine forgiving the offender, they did indeed report more positive responses. The PRO measure was also used to assess whether justice outcomes modulated positive responses. Indeed, even when participants did not imagine granting forgiveness, their PRO scores increased across the justice conditions - from no justice to retributive justice to restorative justice. When participants did imagine granting forgiveness, PRO scores were higher only for restorative versus retributive justice. In our final comparisons of forgiveness and justice, the results echoed the effects on unforgiveness, anger, and empathy: forgiveness-only imagery prompted higher PRO scores than retributive-justice-only, but did not differ from restorative-justice-only.

Gratitude levels increased across the three justice levels, from no justice to retributive justice to restorative justice when participants did imagine granting forgiveness. When participants did not imagine forgiveness, both retributive justice and restorative justice resulted in greater gratitude compared to no justice, but retributive and restorative justice did not differ from each other. When analyzing forgiveness imagery effects, we found that imagined forgiveness increased gratitude, but only when no justice occurred. This suggests that witnessing justice was potent, and it muted gratitude-forgiveness effects. Finally, for the forgiveness-only and justice-only comparisons, a new pattern emerged: restorative-justiceonly increased gratitude levels compared to forgiveness-only. 


\section{Emotion Dimensions: Arousal, Valence, and Control}

Justice and forgiveness affected the dimensions of emotion rated by participants (valence, arousal, and perceived control). The Justice x Forgiveness interaction was significant for arousal, valence (with negative scaled as 0 for the joystick rating, and positive scaled as 20), and perceived control.

As shown in Table 1, arousal ratings were higher in the no-justice-or-forgiveness condition than in all other conditions. For valence, participants felt significantly less negative and more positive across the justice conditions - from no justice (negative) to retributive justice (moderate) to restorative justice (somewhat positive) when they did not imagine granting forgiveness. When participants did imagine granting forgiveness, the only effect was a difference between moderate valence ratings for no justice compared to positive ratings for restorative justice. In each of the justice conditions, forgiveness imagery (versus no forgiveness) was always rated more positively. Valence levels in the forgiveness-only condition did not differ from either retributive-justice-only or restorative-justice-only.

In the absence of imagining forgiveness, participants reported feeling more in control when some form of justice (retributive or restorative) occurred, compared to no justice. When participants did imagine forgiving, restorative justice was associated with the highest level of perceived control. When assessed at each justice level, imagery of forgiveness increased participants' perceived control when no justice occurred. As with valence and arousal, perceived control did not differ for forgiveness-only compared to retributive-justice-only or restorative-justice-only. Imagery Vividness

Imagery has been found to evoke patterns of physiology and self-report isomorphic to those found in vivo (Cuthbert, Vrana \& Bradley, 1991). The degree of vividness reported, as well as the statistical equivalence of vividness across conditions, bode well for this study.

\section{Physiology Data}

Cardiovascular Measures: Heart Rate and Rate Pressure Product (Figure 1, Panels 1 and 2)

As in other forgiveness imagery research (Witvliet et al., 2001), heart rate showed a significant main effect, with lower heart rate levels both during forgiveness imagery and recovery periods, 
Forgiveness Imagery $F(1,51)=11.07, p \leq .001$ and Forgiveness Recovery $F(1,51)=4.03, p \leq .05$. No justice main effects or interactions were significant, all $F s(2,50)<2.11$.

Justice x Forgiveness interactions showed the same effects during imagery and recovery periods: In the absence of imagining forgiveness, retributive justice prompted lower rate pressure product scores than no justice, Justice $x$ Forgiveness Imagery $F(2,40)=7.10, p \leq .001$ and Justice $x$ Forgiveness Recovery $F(2,40)=5.85, p \leq .001$. The Forgiveness main effect for imagery was significant, $F(1,41)=$ $8.84^{* *}, p \leq .001$. The justice main effects and forgiveness in the recovery period were not significant, Fs $\leq 3.19$.

Skin Conductance Levels (Figure 1, Panel 3)

A Justice $x$ Forgiveness interaction occurred during imagery (and became a trend during the recovery period), Justice x Forgiveness Imagery $F(2,44)=5.41, p \leq .001$, Justice x Forgiveness Recovery $F(2,44)=2.85, p \leq .07$. In the absence of forgiveness imagery, restorative justice was associated with lower skin conductance levels compared to retributive justice. All Justice and Forgiveness Fs $\leq 2.63$. Facial EMG: Orbicularis Oculi and Corrugator (Figure 1, Panels 4 and 5)

A Justice $\mathrm{x}$ Forgiveness interaction showed a significant pattern during imagery that became a trend during the recovery period: muscle tension under the eye was significantly lower when participants imagined forgiving (versus no forgiveness imagery), but only when no justice occurred, Justice $\mathrm{x}$ Forgiveness Imagery $F(2,50)=4.35, p \leq .05$, Justice x Forgiveness Recovery $F(2,50)=2.96, p \leq .07$. Forgiveness imagery was associated with calmer EMG, Forgiveness Imagery $F(1,51)=9.32, p \leq .001$. Justice effects and Forgiveness in the recovery period were not significant, all Fs $\leq 2.02$.

For the corrugator, a significant forgiveness main effect occurred during the imagery periods: when participants imagined forgiving, they had lower corrugator EMG scores (i.e., less furrowing of the brow muscle) than when they did not imagine granting forgiveness, Forgiveness Imagery $F(1,51)=6.36$, $p \leq .05$. All other effects during imagery and the recovery period were not significant, all $F \mathrm{~s} \leq 1.59$. 


\section{Discussion}

Victims may address their experiences of injustice and associated unforgiveness by pursuing justice and/or forgiveness. We view justice as a problem-focused approach (cf. Folkman \& Moskowitz, 2000) that may reduce the injustice gap and — theoretically—reduce its associated unforgiveness (Worthington \& Scherer, 2004). The current study garnered evidence for this prediction. Moving from no-justice to retributive to restorative justice generally reduced negative emotion and unforgiving motivations while increasing positive emotion, empathy, prosocial forgiveness responses, and gratitude. Many effects were evident only when victims did not focus on forgiving the offender. For example, restorative justice calmed sweat responses, and retributive justice calmed cardiovascular stress as indicated by rate pressure products (versus the no justice comparison). However, when victims did focus on forgiving the offender, the justice effects were generally muted.

In contrast to justice, we conceptualize forgiveness as an emotion-focused coping strategy used to reduce the unforgiveness that is theoretically associated with an injustice gap (Worthington \& Scherer, 2004). Worthington and Scherer argued that although decisional forgiveness may involve reappraisal of one’s situation and could be considered a problem-focused strategy used to resolve relational problems (cf. Folkman \& Moskowitz, 2000), emotional forgiveness is primarily an emotion-focused coping response that juxtaposes positive emotions against the negative emotions of unforgiveness. Although not a direct test of this assertion, the current data are consistent with this view. Regardless of justice outcome, a focus on forgiving the offender was always associated with greater positive valence, empathy, and positive prosocial responses, and with lower unforgiving motivations, anger, heart rate, and corrugator (brow) EMG.

Although problem-focused approaches and emotion-focused approaches each have benefits, neither has been found to be consistently superior (Park, Folkman, \& Bostrom, 2001). It may be that the problem-focused approach of seeking justice may be superior in reducing unforgiveness when direct action is possible, whereas forgiving one’s offender may be more effective in reducing one’s unforgiveness when it is not possible to take direct action (Exline et al., 2003; Worthington \& Scherer, 
2004). Justice and forgiveness may both be conceived of in prosocial ways (Karremans \& Van Lange, 2005) and may be pursued independently, sequentially, or simultaneously. In addition, experiencing some justice - whether retributive or restorative - is thought to narrow the injustice gap and thereby make forgiveness more likely because there is less injustice (and likely less unforgiveness) to transcend. Previously, Karremans and Van Lange (2005) found that priming justice did indeed prompt higher forgiveness scores. Consistent with their findings, the current study found that — even when participants did not imagine forgiving — retributive and restorative justice outcomes were associated with lower unforgiveness (i.e., TRIM scores) and anger, as well as greater empathy, positive responses toward the offender, and positive emotional valence.

\section{Addressing the Power of Forgiveness and Restorative Justice}

A collective assessment of the variables in this study emphasizes the value of forgiveness and restorative justice in fostering positive responses and eclipsing negative ones. Consistently, a focus on forgiveness was associated with reduced unforgiving motivations and anger. Furthermore, in line with Worthington and Wade’s (1999) and Wade and Worthington’s (2002) emotional juxtaposition hypothesis, forgiveness imagery also increased empathy, positive responses toward the offender, and positive emotional valence regardless of justice outcome. In the absence of justice, imagery of forgiveness (versus no forgiveness) increased gratitude and perceived control, and reduced arousal ratings.

Imagery of granting forgiveness had a significant effect of calming physiology that is specifically linked with arousal (heart rate) and negative valence (corrugator EMG at the brow) during imagery (Witvliet \& Vrana, 1995). Regardless of the justice outcome, granting forgiveness was associated with lower heart rate and brow tension levels, consistent with other research on forgiveness of real-life offenders (Witvliet et al., 2001). The calmer heart rate pattern continued into the forgiving recovery period as well. For the eye muscle (orbicularis oculi) EMG—also linked to imagery arousal (Witvliet \& Vrana, 1995)—forgiveness imagery was associated with less tension, particularly when no justice outcome occurred. 
In the context of forgiveness imagery, the most interesting justice effects were generally associated with restorative justice. Restorative justice was more potent than retributive justice in reducing unforgiving motivations and anger, and increasing gratitude and positive responses toward the offender. Restorative justice also exceeded no justice in reducing anger and increasing gratitude, positive emotional valence, and perceived control. These results are consistent with research by Hodgins and Liebeskind (2003): participants in the role of victim reduced their negative comments and increased their positive comments when they read perpetrator concessions that acknowledged responsibility and apologized fully, as compared to acknowledgements of responsibility that tried to excuse the behavior, and refusals which neither took responsibility nor apologized. As pointed out by Armour and Umbreit (2005), restorative justice programs have safeguards in place to prevent implying that victims ought to forgive, but there appear to be features intrinsic to restorative justice that facilitate victim well-being in comparison to retributive justice as well as no justice.

The crime and justice scenario context of the present study apparently induced different forgiveness-related physiology than research using non-crime interpersonal transgression imagery (Witvliet et al., 2001) and interviews (Lawler et al., 2003). Unlike Witvliet et al. (2001), we did not find a main effect of forgiveness imagery in significantly reducing skin conductance levels compared to unforgiveness. Still, the current results echo those findings because the current restorative-justice-only condition—which evoked less sweating—spontaneously evoked self-reports that were statistically equivalent to the forgiveness imagery condition.

A direct comparison of forgiveness-only and restorative-justice-only conditions showed that they were statistically equivalent in many ways, both reducing levels of unforgiving motivations, anger, and arousal, and in increasing levels of empathy, forgiveness, positive emotional valence, and perceived control. As Dickey (1998) has argued, "Restorative justice has much in common with forgiveness. It is not forgetting; it is not condoning or pardoning; it is not indifference...it is not inconsistent with punishment; it does not wipe out the wrong or deny it. Indeed, it relies on recognition of the wrong so that repair can occur. It also relies on the taking of responsibility for the wrong in a personal and social way” 
(p. 108). Nevertheless, as Armour and Umbreit (2005) have highlighted, restorative justice approaches do not explicitly suggest forgiveness, and mediators are trained to be neutral while respectful; thus, when victims forgive, it is because they have chosen to grant forgiveness.

For one self-report measure only, imagery of restorative justice exceeded imagery of granting forgiveness: gratitude. Emmons and Shelton (2002) have proposed that gratitude not only grows out of empathy for the other party, but also intensifies when a personal, positive outcome clearly results from the actions of another. In the current study’s restorative justice condition, participants increased their empathy for the offender. They also witnessed the offender's remorse and received restitution, key elements for promoting gratitude in Emmons and Shelton’s (2002) conceptualization. In Lazarus’ (1999) view, gratitude is one's natural response to receiving a gift that is given in an uncomplicated way (i.e., without “strings" or manipulation). Witnessing remorse and receiving restitution, as described in our restorative justice manipulation, were analogous to receiving such a gift. Emmons and McCullough (2003) have found that when people focus on such gifts or blessings (as in the present study's restorative justice conditions) they experience emotional benefits, consistent with the patterns found across self-report measures in the current study.

\section{Retributive Justice}

The main pattern of results was that retributive justice reduced negative self-reports and increased positive self reports compared to no justice-but only in the absence of forgiveness. In the presence of imagined forgiveness, retributive justice was associated only with increased gratitude.

Physiologically, retributive justice was associated with significantly lower stress-related rate pressure product scores than no justice (in the absence of forgiveness imagery). In light of Lawler et al's (2003) forgiveness effect on rate pressure products, it is interesting that all three of the forgiveness conditions plus the restorative justice condition (which often had self-report effects paralleling imagined forgiveness) showed similarly moderate rate pressure product scores compared to the high rate pressure product scores in the no-justice-or-forgiveness condition (Figure 1, Panel 2). By further contrast, the low rate pressure product scores in the retributive-justice-only condition suggest that this way of narrowing 
the theoretical injustice gap—-punishing the offender without requiring the victim's personal emotional involvement—was associated with reduced stress.

\section{Stress and Health}

Collectively, these self-report and physiological data are generally consistent with Worthington and Scherer's (2004) propositions. First, these data indirectly support the proposition that unforgiveness is stressful. When no justice outcome occurred and the participant ruminated about the injustice gap created by the burglar's behavior (i.e., the discrepancy between the victim's current situation and what would have to happen to rectify the situation), participants reported the most extreme levels of unforgiving motivations (i.e., TRIM scores), negative valence, arousal, fear, and anger, as well as the lowest levels of perceived control for this condition (see Table 1). ${ }^{3}$ As depicted in Figure 1, heart rate, rate pressure product, skin conductance, orbicularis oculi and corrugator EMG deltas were high for this unforgiving condition. Rate pressure products—the measure most indicative of stress--were significantly elevated for no-justice-or-forgiveness in contrast to all five of the other conditions during imagery, and in contrast to three of the other conditions in the recovery period. These data are consistent with other unforgiveness research finding modest baseline cortisol differences in dispositionally unforgiving versus forgiving people, and differences in cortisol reactivity for people in unhappy or acrimoniously terminated relationships versus happy relationships (Berry \& Worthington, 2001).

The current study more directly assessed the propositions that justice and forgiveness can each reduce unforgiveness. Justice, forgiveness, and their interaction reduced unforgiving motivations (i.e., TRIM scores), anger, and fear (cf. main effects only). These findings are consistent with Wade and Worthington's (2002) findings that while virtually all students who completely forgave an offender had low unforgiveness, many students who reported zero forgiveness also had little or no unforgiveness. This suggested that in addition to granting forgiveness, possible alternatives such as witnessing remorse, receiving an apology, or having an offender experience justice may lower a victim’s unforgiveness.

In terms of justice, both retributive and restorative justice outcomes resulted in less unforgiveness than did no justice. Furthermore, restorative justice was associated with lower unforgiving motivations 
and emotions than retributive justice. Still, tests of forgiveness showed that regardless of the justice outcome, forgiveness substantially reduced unforgiveness. Furthermore, forgiveness reduced even covert expressions of negative emotion at the corrugator (brow) muscle.

The idea that forgiveness may be related to health received some indirect support. Greater heart rate increases occurred when forgiveness was not granted versus granted during imagery periods, and this difference remained statistically significant into the recovery period, similar to findings by Witvliet et al. (2001). Research by Brosschot and Thayer (1998) suggests that cardiovascular recovery may be even more critical for health than is reactivity. They argue that slow cardiac recovery, whether on its own or in addition to high cardiac reactivity, may be a key factor in the link between hostility and cardiovascular disease. However, as Harris and Thoresen (2005) emphasize, the relationship between forgiveness and health has not been established, and if it is, it will likely be a nuanced relationship.

Our proposed corollary—-that justice may also decrease physiological indicators of heightened stress (i.e., negative high arousal emotion)—also received indirect support. In other research, Vermunt and Steensma (2005) have identified that stress can be reduced through procedural and distributive justice in the workplace. In our research, we found that rate pressure products (linked with myocardial oxygen demand, and indicative of stress) as well as skin conductance levels (strongly linked with sympathetic nervous system arousal) responded to an interaction of justice and forgiveness, in which justice had an effect only if forgiveness was absent. Notably, the effect for rate pressure product was significant in the recovery as well as imagery period. Although heart rate, rate pressure products, and skin conductance levels are not health outcome measures per se, they are indicators of stress, which has been shown repeatedly to be related to health outcomes.

In spite of the initial appearance of consistencies with Worthington and Scherer's (2004) propositions, the case is far from settled. Witvliet et al. (2001) observed that the experimental paradigm employed in the current study likely provides a conservative indication of patterns that would naturally occur in response to real-life offenders. One could theorize that if people’s anger and sympathetic nervous system and cardiovascular reactivity — as well as impaired recovery_-were perpetuated over the long 
term, even subtle effects could accumulate over time to pose a risk to health. At present, national survey data (Toussaint, Williams, Musick, \& Everson, 2001) and Lawler et al.’s (2003) data link forgiveness to lower levels of reported illness symptoms. However, much careful research is needed to determine the extent to which unforgiveness may be similar to or different from the particular features and expressions of stress and hostility that are shown to bear a relationship to health outcomes (Harris \& Thoresen, 2005). It remains for future studies to target more explicitly the relationship of not only forgiveness, but also justice processes and outcomes to health effects.

\section{Cautions and Future Directions}

We close with two observations and cautionary notes. First, our goal was to make scripts as externally valid as possible, and so we consulted with professionals who work with both retributive and restorative justice responses to burglary. Because in the real-world and in this experiment, each outcome involved several elements, we cannot say which particular elements alone and in combination are responsible for the results. Neither can we predict what the long-term effects of any of these justice or forgiveness outcomes might have for the victim, and so to complement the experimental laboratory work, we ultimately need longitudinal research in the field, although numerous constraints will make such psychophysiological research both difficult and costly.

Second, our research suggests that experiencing justice does not necessarily reduce one’s forgiveness motives or experience. In fact, experiencing some measure of justice seems to promote the experience of positive thoughts, feelings, and behaviors toward an offender (i.e., increased PRO scores). Worthington and Scherer (2004) argued that this is reasonable because an increased sense of justice narrows the injustice gap, making it easier to transcend by experiencing forgiveness. However, what happens when people grant forgiveness? Our manipulation to imagine granting forgiveness included cognitive and emotional elements intended to foster emotional forgiveness. We found that the forgiveness imagery eventuated in increased self-reports of forgiving and other positive emotions, and attenuated heart rate (associated with reduced emotional arousal during imagery) and brow tension responses (associated with reduced negative valence during imagery). Although these results look positive, might 
there be a negative side—-such as if efforts to forgive reduce or eliminate people's justice motive (Ross \& Miller, 2002)? One important concern raised by Wiesenthal and others (see Wiesenthal, Cargas, \& Fetterman, 1997, for several examples), is that by forgiving wrongdoers, victims may not be motivated to pursue justice. Although we did not address this issue in the present study, it is a concern that warrants further investigation with regard to property crimes and crimes against persons that vary in severity.

\section{Conclusion}

The present data suggest that both forgiveness and justice induce self-reported changes in motivations and emotions, with restorative justice reducing victims' unforgiving motivations and anger, and increasing their positive responses to the offender more than retributive justice. In terms of physiology, forgiveness was associated with less negative and aroused response patterns, and justice benefits emerged only in the absence of forgiveness. These results further suggest that even if the pursuit of justice is impeded, victims can take action that may hold some subjective and physiological benefits for themselves. Even while waiting for retributive or restorative justice outcomes to finalize, victims have the option of granting forgiveness, without having to tell the offender, or anyone else. In that act of giving, victims may be able to increase their positive emotions and reduce their unforgiveness and its associated subjective and physiological signs of negative and aroused (i.e., stressful) emotion. 


\section{References}

Armour, M.P., \& Umbreit, M.S. (2005). The paradox of forgiveness. In E.L. Worthington, Jr. (Ed.), Handbook of forgiveness. (pp. 491-503). New York: Routledge.

Batson, C.D., Bolen, M.H., Cross, J.A., \& Neuringer-Benfiel, H.E. (1986). Where is the altruism in the altruistic personality? Journal of Personality and Social Psychology, 50, 212-220.

Bazemore, G. (1998). Restorative justice and earned redemption: Communities, victims, and offender reintegration. American Behavioral Scientist, 41, 768-813.

Berry, J.W., \& Worthington, E.L., Jr. (2001). Forgiveness, relationship quality, stress while imagining relationship events, and physical and mental health. Journal of Counseling Psychology, 48, 447455.

Braithwaite, J. (1989). Crime, shame, and reintegration. Cambridge: Cambridge University Press.

Brosschot, J.F., \& Thayer, J.F. (1998). Anger inhibition, cardiovascular recovery, and vagal function: A model of the link between hostility and cardiovascular disease. Annals of Behavioral Medicine, 20, 326-332.

Brown, R.P. (2005). When apologies fail: Mea culpa and the intimacy effect. In R. Brown \& M. Wohl (Chairs), Frontiers in forgiveness research. Symposium conducted at the Society for Personality and Social Psychology Annual Meeting, New Orleans, LA.

Cohen, R.L. (2001). Provocations of restorative justice. Social Justice Research, 14, 209-232.

Cook E.W. III., Atkinson, L., \& Lang, K.G. (1987). Stimulus control and data acquisition for IBM PC’s and compatibles. Psychophysiology, 24, 726-727.

Cuthbert, B.N., Vrana, S.R. \& Bradley, M. (1991). Imagery: Function and physiology. In P.K. Ackles, J.H. Jennings, and M.G.H. Coles (Eds.), Advances in psychophysiology (Vol. 4, pp. 1-42). London: Jessica Kingsley Publishers.

Darley, J. (2002). Just punishments: Research on retributional justice. In M. Ross \& D. T. Miller (Eds.), The justice motive in everyday life (pp. 314-333). New York: Cambridge University Press. 
Darley, J. M., \& Pittman, T. S. (2003). The psychology of compensatory and retributive justice. Personality and Social Psychology Review, 7, 324-336.

Dickey, W.J. (1998). Forgiveness and crime: The possibilities of restorative justice. In R.D. Enright \& J. North (Eds.), Exploring forgiveness (pp.106-120). Madison, WI: University of Wisconsin Press.

Enright, R.D., \& Fitzgibbons, R.P. (2000). Helping clients forgive: An empirical guide for resolving anger and restoring hope. Washington, DC: American Psychological Association.

Emmons, R.A., \& McCullough, M.E. (2003). Counting blessings versus burdens: An experimental investigation of gratitude and subjective well-being in daily life. Journal of Personality and Social Psychology, 84, 377-389.

Emmons, R.A., \& Shelton, C.M. (2002). Gratitude and the science of positive psychology. In C.R. Snyder \& S.J. Lopez (Eds.), Handbook of positive psychology (pp. 459-471). New York: Oxford University Press.

Exline, J.J., Worthington, E.L., Jr., Hill, P., \& McCullough, M.E. (2003). Forgiveness and justice: A research agenda for social and personality psychology. Personality and Social Psychology Review, 7, 337-348.

Finkel, E.J., Rusbult, C.E., Kumashiro, M., \& Hannon, P.A. (2002). Dealing with betrayal in close relationships: Does commitment promote forgiveness? Journal of Personality and Social Psychology, 82, 956-974.

Folkman, S., \& Moskowitz, J.T. (2000). Positive affect and the other side of coping. American Psychologist, 55, 647-654.

Fowles, D.C., Christie, M.J., Edelberg, R., Grings, W.W., Lykken, D.T., \& Venables, P.H. (1981). Publication recommendations for electrodermal measurements. Psychophysiology, 18, 232-239.

Frantz, C.M., \& Bennigson, C. (2005). Better late than early: The influence of timing on apology effectiveness. Journal of Experimental Social Psychology, 41, 201-207.

Freedman, S. (1998). Forgiveness and reconciliation: the importance of understanding how they differ. Counseling and Values, 42, 200-216. 
Fridlund, A.J., \& Cacioppo, J.T. (1986). Guidelines for human electromyographic research.

Psychophysiology, 23, 567-589.

Green, S.B., Salkind, N.J., \& Akey, T.M.. (2000). Using SPSS for Windows: Analyzing and understanding data. Upper Saddle River, NJ: Prentice Hall.

Harris, A.H.S., \& Thoresen, C.E. (2005). Forgiveness, unforgiveness, health, and disease. In E.L. Worthington, Jr. (Ed.), Handbook of forgiveness. (pp. 321-348). New York: Routledge.

Hill, P.C., Exline, J.J., \& Cohen, A.B. (2005). The social psychology of justice and forgiveness in civil and organizational settings. In E.L. Worthington, Jr. (Ed.), Handbook of forgiveness. (pp. 477490). New York: Routledge.

Hodes, R.L., Cook, P.W., \& Lang, P.J. (1985). Individual differences in autonomic response: Conditioned association or conditioned fear? Psychophysiology, 22, 545-560.

Hodgins, H.S., \& Liebeskind, E. (2003). Apology versus defense: Antecedents and consequences. Journal of Experimental Social Psychology, 39, 297-316.

Huang, S.T.T, \& Enright, R.D. (2000). Forgiveness and anger-related emotions in Taiwan: Implications for therapy. Psychotherapy: Theory, Research, Practice, Training, 37, 71-79.

Karremans, J.C., \& Van Lange, P.A.M. (2005). Does activating justice help or hurt in promoting forgiveness? Journal of Experimental Social Psychology, 41, 290-297.

Kitamura, K., Jorgensen, C.R., Gebel, F.L., \& Wang, Y. (1972). Hemodynamic correlates of myocardial oxygen consumption during upright exercise. Journal of Applied Physiology, 32, 516-522.

Lang, P.J. (1995). The emotion probe: Studies of motivation and attention. American Psychologist, 50, 372-385.

Lawler, K.A., Younger, J.W., Piferi, R.L., Billington, E., Jobe, R., Edmondson, K., \& Jones, W.H. (2003). A change of heart: Cardiovascular correlates of forgiveness in response to interpersonal conflict. Journal of Behavioral Medicine, 26, 373-393.

Lazarus, R.S. (1999). Stress and emotion: A new synthesis. New York: Springer Publishing. 
McCullough, M.E., Fincham, F.D., \& Tsang, J. (2003). Forgiveness, forbearance, and time: The temporal unfolding of transgression-related interpersonal motivations. Journal of Personality and Social Psychology, 84, 540-557.

McCullough, M.E., Rachal, K.C., Sandage, S.J., Worthington, E.L., Jr., Brown, S.W., \& Hight, T.L. (1998). Interpersonal forgiving in close relationships II: Theroretical elaboration and measurement. Journal of Personality and Social Psychology, 75, 1586-1603.

McCullough, M.E., Worthington, E.L., Jr., \& Rachal, K.C. (1997). Interpersonal forgiving in close relationships. Journal of Personality and Social Psychology, 73, 321-336.

Park, C.L., Folkman, S., \& Bostrom, A. (2001). Appraisals of controllability and coping in caregivers and HIV+ men: Testing the goodness-of-fit hypothesis. Journal of Consulting and Clinical Psychology, 69, 481-488.

Ross, M., \& Miller, D.T. (Eds). (2002). The justice motive in everyday life. New York: Cambridge University Press.

Solomon, R.C. (1999). Justice v. vengeance: On law and the satisfaction of emotion. In S.A. Bandes (Ed.), The passions of law (pp. 123-148). New York: New York University Press.

Toussaint, L.L., Williams, D.R., Musick, M.A., \& Everson, S.A. (2001). Forgiveness and health: Age difference in a U.S. probability sample. Journal of Adult Development, 8, 249-257.

Tyler, T. R., Boeckmann, R. J., Smith, H. J., \& Huo, Y. J. (1997). Social justice in a diverse society. Boulder: Westview.

Umbreit, M.S. (2001). The handbook of victim offender mediation: An essential guide to practice and research. San Francisco: Jossey-Bass.

U.S. Department of Justice Federal Bureau of Investigation. (2006). Crime in the United States 2005. Retrieved September 29, 2006, from http://www.fbi.gov/ucr/05cius/offenses/property_crime/burglary.html. 
Vermunt, R., \& Steensma, H. (2005). How can justice be used to manage stress in organizations? In J. Greenberg \& J.A. Colquitt (Eds.), Handbook of organizational justice: Fundamental questions about fairness in the workplace (pp. 383-410) Mahwah, NJ: Erlbaum.

Vidmar, N. (2002). Retributive justice: Its social context. In M. Ross \& D. T. Miller (Eds.), The justice motive in everyday life (pp. 291-313). New York: Cambridge University Press.

Wade, N.G., \& Worthington, E.L., Jr. (2002). Overcoming interpersonal offenses: Is forgiveness the only way to deal with unforgiveness? Journal of Counseling and Development, 81, 343-353.

Wiesenthal, S., Cargas, H.J., \& Fetterman, B.V. (1997). The sunflower: On the possibilities and limits of forgiveness. New York: Schocken Books.

Witvliet, C.V.O., Ludwig, T.E., \& Bauer, D. (2002). Please forgive me: Transgressors emotions and physiology during imagery of seeking forgiveness and victim responses. Journal of Psychology and Christianity, 21, 219-233.

Witvliet, C.V.O., Ludwig, T.E., \& Vander Laan, K. (2001). Granting forgiveness or harboring grudges: Implications for emotion, physiology, and health. Psychological Science, 12, 117-123.

Witvliet, C.V.O., \& Vrana, S.R. (1995). Psychophysiological responses as indices of affective dimensions. Psychophysiology, 32, 436-443.

Witvliet, C.V.O., \& Vrana, S.R. (2000). Emotional imagery, the visual startle, and covariation bias: An affective matching account. Biological Psychology, 52, 187-204.

Witvliet, C.V.O., Worthington, E.L., Jr., \& Wade, N.G. (2002). Victims' heart rate and facial EMG responses to receiving an apology and restitution. Psychophysiology, Supplement, 88.

Worthington, E. L. Jr. (2006). Forgiveness and reconciliation: Theory and application. New York: Brunner Routledge.

Worthington, E.L., Jr., \& Drinkard, D.T. (2000). Promoting reconciliation through psychoeducational and therapeutic interventions. Journal of Marital and Family Therapy, 26, 93-101. 
Worthington, E.L., Jr., \& Scherer, M. (2004). Forgiveness is an emotion-focused coping strategy that can reduce health risks and promote health resilience: Theory, review, and hypotheses. Psychology and Health.

Worthington, E.L., Jr., \& Wade, N.G. (1999). The psychology of unforgiveness and forgiveness and implications for clinical practice. Journal of Social and Clinical Psychology, 18, 385-418.

Zehr, H. (1995). Changing lenses: A new focus on crime and justice. Scottdale, PA: Herald Press. 


\section{Appendix A}

Table A1

Latin Square Order of Conditions Used Across Participants for Questionnaire (Study Section I)

\begin{tabular}{ll}
\hline$\underline{\text { Order }}$ & Imagery Script Sequence \\
\hline 1 & Ret + Forg $\rightarrow$ Rest + Forg $\rightarrow$ No Just No Forg $\rightarrow$ Forg $\rightarrow$ Rest Only $\rightarrow$ Ret Only \\
2 & Forg $\rightarrow$ Ret + Forg $\rightarrow$ Ret Only $\rightarrow$ No Just No Forg $\rightarrow$ Rest + Forg $\rightarrow$ Rest Only \\
3 & No Just No Forg $\rightarrow$ Ret Only $\rightarrow$ Rest Only $\rightarrow$ Rest + Forg $\rightarrow$ Ret + Forg $\rightarrow$ Forg \\
5 & Rest Only $\rightarrow$ Forg $\rightarrow$ Ret + Forg $\rightarrow$ Ret Only $\rightarrow$ No Just No Forg $\rightarrow$ Rest + Forg \\
6 & Ret Only $\rightarrow$ Rest Only $\rightarrow$ Rest + Forg $\rightarrow$ Ret + Forg $\rightarrow$ Forg $\rightarrow$ No Just No Forg \\
\hline
\end{tabular}

Note. Ret + Forg is Restorative Justice Plus Forgiveness. Rest + Forg is Restorative Justice Plus Forgiveness. No Just No Forg is No Justice or Forgiveness. Forg is Forgiveness. Rest Only is Restorative Justice Only. Ret Only is Retributive Justice Only. 
Table A2

Latin Square Order Used Across Participants for Imagery and Physiology (Study Section II)

Condition

\begin{tabular}{|c|c|c|c|}
\hline Order & Imagery Block & High Tone Imagery Type & Low Tone Imagery Type \\
\hline \multirow[t]{3}{*}{1} & 1 & Retributive + Forgiveness & Restorative + Forgiveness \\
\hline & 2 & No Justice No Forgiveness & Forgiveness only \\
\hline & 3 & Restorative only & Retributive only \\
\hline \multirow[t]{3}{*}{2} & 1 & Forgiveness only & Retributive + Forgiveness \\
\hline & 2 & Retributive only & No Justice No Forgiveness \\
\hline & 3 & Restorative + Forgiveness & Restorative only \\
\hline \multirow[t]{3}{*}{3} & 1 & No Justice No Forgiveness & Retributive only \\
\hline & 2 & Restorative only & Restorative + Forgiveness \\
\hline & 3 & Retributive + Forgiveness & Forgiveness only \\
\hline \multirow[t]{3}{*}{4} & 1 & Restorative + Forgiveness & No Justice No Forgiveness \\
\hline & 2 & Forgiveness only & Restorative only \\
\hline & 3 & Retributive only & Retributive + Forgiveness \\
\hline \multirow[t]{3}{*}{5} & 1 & Restorative only & Forgiveness only \\
\hline & 2 & Retributive + Forgiveness & Retributive only \\
\hline & 3 & No Justice No Forgiveness & Restorative + Forgiveness \\
\hline \multirow[t]{3}{*}{6} & 1 & Retributive only & Restorative only \\
\hline & 2 & Restorative + Forgiveness & Retributive + Forgiveness \\
\hline & 3 & Forgiveness only & No Justice No Forgiveness \\
\hline
\end{tabular}

Note. In each block, four high and four low tones occurred in a quasi random order. 


\section{Appendix B}

Incident Script.

DIRECTIONS: Please read the following scenario. Place yourself in this situation as best you can. Take time to vividly imagine that this has really happened to you. Take a few moments to vividly imagine these events as if they were actually happening to you right now. Focus on the thoughts, feelings, and physical reactions you would be having.

You have been worried all day. Soon after leaving your house this morning, you realized that you had left your wallet on your dresser at home. Your wallet not only contains a large amount of money, but your credit cards, check card, driver's license, and student ID. Finally, after a particularly long day at school, you have the opportunity to return to your place to retrieve your wallet. As you approach your door, you fumble for your keys, but they aren’t in your pocket. Suddenly you notice your door is partly open. You try to remember if you locked the door that morning, thinking again of your wallet, and you enter your place.

You close the door behind you and set down your bag like you do every day when you come home. Then it hits you. Your belongings and furniture are all scattered and misplaced. Drawers in your desk are hanging open, papers and books lay thrown about. The wastebasket is toppled over, expelling the paper trash across the floor. The room looks strangely empty. Stunned, you realize your TV and stereo equipment are gone. Your heart beats more rapidly as the reality of the situation sinks in. You realize that you have been robbed. You walk into the bathroom area, and find that even here the burglar went through your personal belongings. The burglar obviously avoided no area. Then a sweeping panic takes over you as you think of your wallet. Your heart pounds and you tense up as you frantically search the place where you usually keep your keys and wallet, but they are not there. You race from room to room, trying to think whether perhaps you placed them somewhere else, hoping that the burglar did not find them. As the minutes wear on, it dawns on you that you had parked nearby. Scared, you race out the door searching for your vehicle. You see a different car where yours should be. You can't believe this is actually happening 
to you. What kind of person would do such a thing? Your wallet, house keys, vehicle, stereo, and TV were stolen, and you have no idea who might have taken them. You feel so violated. On top of that it will even be hassle to cancel credit cards and get a new driver’s license and student ID.

In the next few hours, you make the report to the appropriate authorities and make a list of the things that are missing. At the top of the list is your vehicle, wallet and keys. Then there's your stereo and TV. Beyond that, you realize the burglar also stole fifty dollars, some loose change, your watch, and a treasured keepsake from someone you love. You give this list to the authorities and they inform you that they will get in touch with you if they find a suspect.

Six Possible Outcome Scripts. DIRECTIONS: Suppose this is how the burglary incident turns out. Try to vividly imagine these events as if they were actually happening to you right now. Focus on the thoughts, feelings, and physical reactions you would be having if this really happened to you.

No Justice or Forgiveness Script. A few days following the burglary, the investigating detective contacts you. The police have been unable to identify any suspects that they believe burglarized your place and stole your vehicle.

The day after hearing from the detective, you think about how violated you feel and what it will take to start the long, arduous process of replacing your missing things. You think of what it was like once before when you lost your wallet, and you know the trouble that replacing all your cards will cause you. You'll have to call your credit card companies to cancel your cards and try to get replacements. You'll have to go back to school to replace your ID card. Then, you'll have to go all the way to the department of motor vehicles (DMV) and wait in a really long line for a new driver's license. You know that you will have to buy another watch. You figure you will have to go without a stereo and TV for awhile until you can save enough money to buy new ones. Then, you realize there is no way you can ever replace your treasured keepsake. You think about how complicated it all is. You'll have to skip classes and take off from work to do deal with everything. It will be a huge hassle. All of this is made worse because your vehicle is gone. How are you going to get to all these places? Then you think about how much your insurance will actually cover, and how much money it will cost you to replace your vehicle- 
to say nothing of the time it will take to find another vehicle. You can’t believe you haven't heard anything since the incident. You're overwhelmed by your feelings about being robbed and wonder if the thief even feels guilty about it. You think about what should happen to this criminal and how you'd like to get back at this thief.

Forgiveness Alone Script. A few days following the burglary, the investigating detective contacts you. The police have been unable to identify any suspects that they believe burglarized your place and stole your vehicle.

As you think about the situation, you consider what it would mean to forgive the person responsible for the burglary and theft. You realize that this person should be held accountable for the crime. At the same time, your hurt, bitterness, and anger are eating at you and aren't helping to resolve the situation. In response, you intentionally forgive and thus you let go of your hurt and revenge and instead focus on what compassionate response you could genuinely have for this person. You try to see things from the offender's perspective and focus on the fact that this is a human being. It can be hard to empathize, so perhaps you can feel sorry for someone who drops to the level of stealing from others. You think about what factors in this person's life might have influenced this person's behavior. You find it in your heart to genuinely hope that this person will not only turn away from crime, but also experience a positive life change and become a productive member of society.

Retributive Justice Alone Script. A few days following the burglary, the investigating detective contacts you. The police have apprehended an individual who they believe burglarized your place and stole your vehicle.

Several weeks and months have gone by as you have waited for the criminal trial of the person charged with burglarizing your residence and stealing your vehicle. The perpetrator has to go through a public trial, which gets press coverage in your local paper. The result of the trial is that the perpetrator is found guilty and is sentenced to 1 year in jail with the possibility of parole. The perpetrator will also have to pay the county $\$ 21$ per day of actual time spent in jail. 
Retributive Justice Plus Forgiveness Script. A few days following the burglary, the investigating detective contacts you. The police have apprehended an individual who they believe burglarized your place and stole your vehicle.

Several weeks and months have gone by as you have waited for the criminal trial of the person charged with burglarizing your residence and stealing your vehicle. The perpetrator has to go through a public trial, which gets press coverage in your local paper. The result of the trial is that the perpetrator is found guilty and is sentenced to 1 year in jail with the possibility of parole, plus a fee of \$21 per day that the perpetrator is in jail.

You realize that this person will be punished for the crime. Even though the person will receive punishment from society, you are concerned with your personal response to the person. You consider what it would mean to forgive this person. You try to intentionally forgive and thus you let go of your hurt and revenge, and instead focus on what compassionate response you could genuinely have for this person. You try to see things from the offender's perspective and focus on the fact that this is a human being. It can be hard to empathize, so perhaps you can feel sorry for someone who drops to the level of stealing from others. You think about what factors in this person's life might have influenced this person's behavior. You find it in your heart to genuinely hope that this person will not only turn away from crime, but also experience a positive life change and become a productive member of society.

Restorative Justice Alone Script. A few days following the burglary, the investigating detective contacts you. The police have apprehended an individual who they believe burglarized your place and stole your vehicle.

Several weeks and months have gone by as you have waited for a restorative justice program intervention. The restorative justice program is designed to give both perpetrators and victims a sense of justice, while assisting the perpetrator in being restored to the community. As it turns out, the perpetrator who burglarized your place and stole your vehicle expresses remorse and offers to replace the stolen 
objects. Your wallet, watch, TV, stereo, treasured keepsake, and vehicle are returned. The perpetrator also commits to 200 hours of community service, and you get to choose where this is done.

Restorative Justice Plus Forgiveness Script. A few days following the burglary, the investigating detective contacts you. The police have apprehended an individual who they believe burglarized your place and stole your vehicle.

Several weeks and months have gone by as you have waited for a restorative justice program intervention. The restorative justice program is designed to give both perpetrators and victims a sense of justice, while assisting the perpetrator in being restored to the community. As it turns out, the perpetrator who burglarized your place and stole your vehicle expresses remorse and offers to replace the stolen objects. Your wallet, watch, TV, stereo, treasured keepsake, and vehicle are returned. The perpetrator also commits to 200 hours of community service, and you get to choose where this is done.

You realize that this person has returned your belongings and will engage in community service both to make up for some of the problems caused and to restore this person to the community. Even though restorative justice is occurring, you are concerned with your personal response to the person. You consider what it would mean to forgive this person. You try to intentionally forgive and thus you let go of your hurt and revenge, and instead focus on what compassionate response you could genuinely have for this person. You try to see things from the offender's perspective and focus on the fact that this is a human being. It can be hard to empathize, so perhaps you can feel sorry for someone who drops to the level of stealing from others. You think about what factors in this person's life might have influenced this person's behavior. You find it in your heart to genuinely hope that this person will not only turn away from crime, but also experience a positive life change and become a productive member of society. 
Table 1

Means for Self-Report Dependent Variables and Results of Analyses of Variance

\begin{tabular}{|c|c|c|c|c|c|c|c|c|c|}
\hline \multirow[b]{3}{*}{ Measure (Range) } & \multirow{3}{*}{$\begin{array}{l}\text { No-Justice- } \\
\text { or- } \\
\text { Forgiveness }\end{array}$} & \multirow{3}{*}{$\begin{array}{c}\text { Retributive- } \\
\text { Justice- } \\
\text { Only }\end{array}$} & \multirow{3}{*}{$\begin{array}{c}\text { Restorative- } \\
\text { Justice- } \\
\text { Only }\end{array}$} & \multirow{3}{*}{$\begin{array}{c}\text { Forgiveness- } \\
\text { Only }\end{array}$} & \multirow{3}{*}{$\begin{array}{l}\text { Retributive- } \\
\text { Justice-Plus- } \\
\text { Forgiveness }\end{array}$} & \multirow{2}{*}{$\begin{array}{l}\text { Restorative- } \\
\text { Justice-Plus- }\end{array}$} & & & \\
\hline & & & & & & & \multirow{2}{*}{\multicolumn{3}{|c|}{ F-equivalent for Wilks’ Lambda }} \\
\hline & & & & & & Forgiveness & & & \\
\hline & & & & & & & $\underline{\text { Justice }}$ & $\underline{\text { Forgiveness }}$ & $\underline{\mathrm{J} \times \mathrm{F}}$ \\
\hline TRIM (12-60) & $44.27^{\mathrm{a}}$ & $38.51^{\mathrm{b}}$ & $33.06^{\mathrm{c}}$ & $31.86^{\text {cde }}$ & $31.95^{\mathrm{d}}$ & $28.80^{\mathrm{e}}$ & $25.33 * * *$ & $78.85 * * *$ & $15.05^{* * *}$ \\
\hline Anger (0-20) & $16.85^{\mathrm{a}}$ & $12.24^{\mathrm{b}}$ & $8.89^{c}$ & $9.20^{\mathrm{cd}}$ & $7.74^{\mathrm{d}}$ & $5.13^{\mathrm{e}}$ & $35.38 * * *$ & $100.40^{* * *}$ & $5.15^{* *}$ \\
\hline Fear $(0-20)$ & 9.32 & 5.11 & 4.52 & 5.80 & 3.72 & 3.13 & $15.88^{* * *}$ & $26.55^{* * *}$ & $2.90^{+}$ \\
\hline Empathy (8-48) & $10.03^{\mathrm{a}}$ & $14.09^{b}$ & $19.85^{\mathrm{c}}$ & $21.84^{\mathrm{cd}}$ & $21.98^{\mathrm{d}}$ & $24.06^{\mathrm{d}}$ & $19.68 * * *$ & $75.58 * * *$ & $14.79 * * *$ \\
\hline PRO (6-30) & $8.56^{\mathrm{a}}$ & $11.29^{\mathrm{b}}$ & $14.27^{\mathrm{C}}$ & $14.90^{\text {cde }}$ & $15.02^{\mathrm{d}}$ & $16.75^{\mathrm{e}}$ & $30.49 * * *$ & $83.03 * * *$ & $10.82 * * *$ \\
\hline Gratitude (0-20) & $3.09^{\mathrm{a}}$ & $9.72^{\mathrm{bcd}}$ & $11.88^{\text {be }}$ & $7.54^{\mathrm{c}}$ & $11.35^{\mathrm{d}}$ & $13.93^{\mathrm{e}}$ & $54.15^{* * *}$ & $31.59 * * *$ & $4.08 *$ \\
\hline Valence (0-20) & $4.15^{\mathrm{a}}$ & $10.06^{\mathrm{b}}$ & $12.74^{\mathrm{C}}$ & $11.21^{\mathrm{bc}}$ & $13.00^{\mathrm{cd}}$ & $15.19^{\mathrm{d}}$ & $37.47 * * *$ & $55.10 * * *$ & $9.74 * * *$ \\
\hline Arousal (0-20) & $15.65^{\mathrm{a}}$ & $10.52^{\mathrm{b}}$ & $8.41^{\mathrm{b}}$ & $7.50^{\mathrm{b}}$ & $7.74^{\mathrm{b}}$ & $7.24^{\mathrm{b}}$ & $13.65^{* * *}$ & $42.68 * * *$ & $11.96 * * *$ \\
\hline Control (0-20) & $5.02^{\mathrm{a}}$ & $10.04^{\mathrm{b}}$ & $12.31^{\mathrm{bc}}$ & $9.57^{\mathrm{b}}$ & $12.35^{\mathrm{b}}$ & $13.49^{\mathrm{C}}$ & $31.03^{* * *}$ & $24.98 * * *$ & $3.86^{*}$ \\
\hline Vividness (0-20) & 13.87 & 13.37 & 13.09 & 12.33 & 13.07 & 13.07 & 0.19 & 0.99 & 1.66 \\
\hline
\end{tabular}


Note. Degrees of freedom vary across dependent variables due to occasional missing data. Degrees of freedom for the TRIM, Batson’s Empathy Adjectives, and PRO: Justice (2,53), Forgiveness (1,54), and Justice x Forgiveness (2,53). Anger, fear, valence, and arousal: Justice (2,51), Forgiveness (1,52), and Justice x Forgiveness (2,51). Gratitude: Justice (2,50), Forgiveness (1,51), and Justice x Forgiveness $(2,50)$. Control: Justice $(2,47)$, Forgiveness $(1,48)$, and Justice x Forgiveness (2,47). Vividness: Justice $(2,52)$, Forgiveness $(1,53)$, and Justice x Forgiveness $(2,52)$.

${ }_{a, b, c, d, e}$ For significant Justice x Forgiveness interactions, different superscripts identify which condition means differ significantly ( $\left.p \leq .004\right)$; means with the same superscript do not differ significantly.

${ }^{* * *} p<.001,{ }^{* *} p<.01, * p<.05,{ }^{+}$indicates a trend of $p<.07$. 
Figure Caption

Figure 1. Physiological reactivity and recovery patterns based on a 4-sec baseline, four 4-sec epochs during active imagery, and two 4-sec epochs of relaxation during the recovery period. For each of the six experiment conditions, the data were averaged across four trials per participant. 

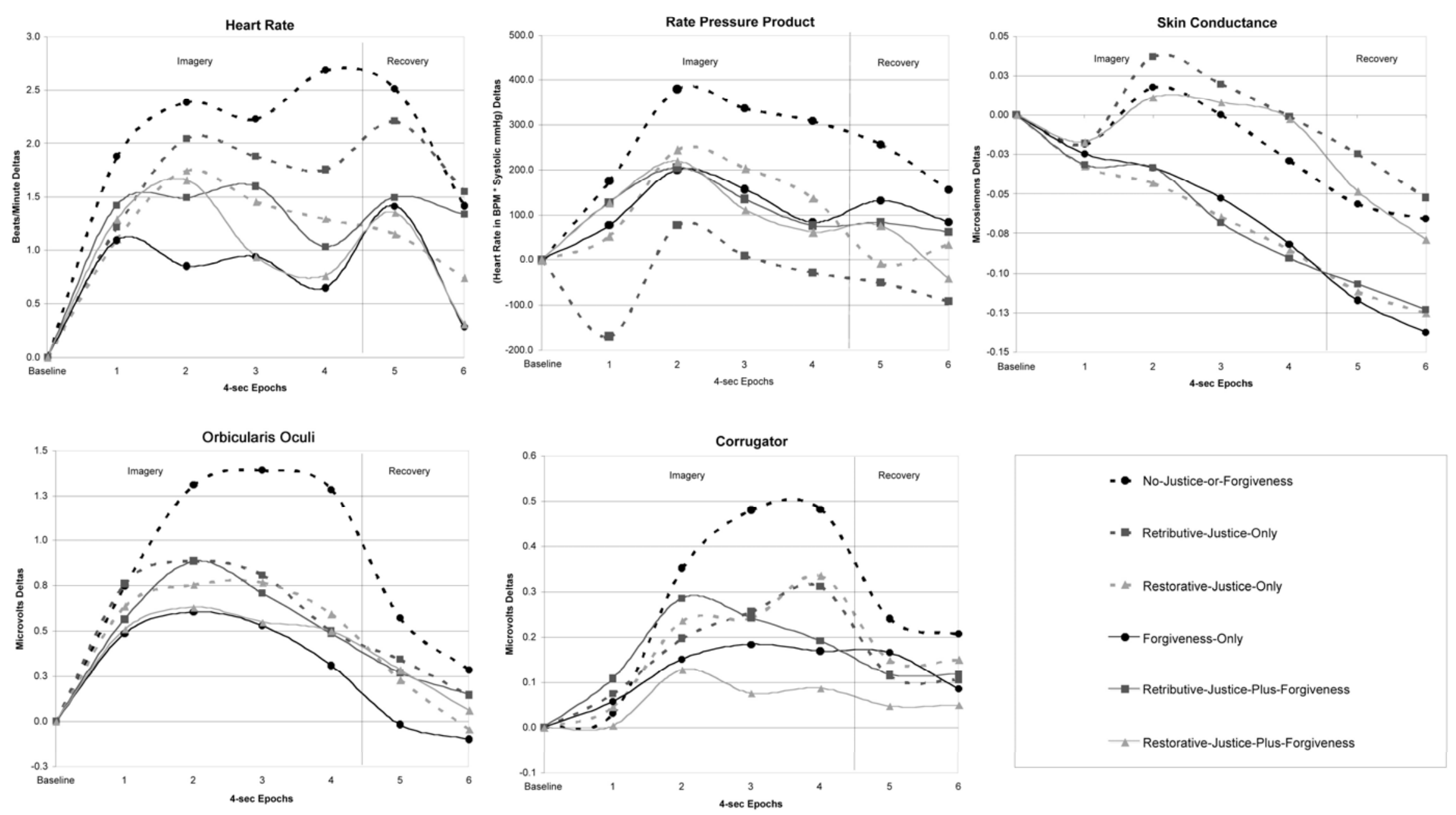


\section{Footnotes}

${ }^{1}$ Physiological data collection cables, headphones, and speaker wire were fed through PVC tubing placed in the shared wall. To time the presentation of tones and collect on-line physiological data, we used a Dell 486 computer and VPM software (Cook, Atkinson, \& Lang, 1987). To measure participant ratings after imagery, we used a joystick and a second Dell 486 with VPM software in the participant room. Imagery and relaxation trials were signaled by auditory tones at three frequencies-high $(1350 \mathrm{~Hz})$, medium $(985 \mathrm{~Hz})$, and low $(620 \mathrm{~Hz})$. The tones were $500 \mathrm{~ms}$ long and $73 \mathrm{~dB}[\mathrm{~A}]$. They were generated by a Coulbourn V85-05 Audio Source Module with a shaped rise time set at $50 \mathrm{~ms}$. The tones were presented through Altec Lansing ACS41 speakers located 2.5 feet to the left of the participant's head during the instructions, and through Optimus Nova 67 headphones during data collection.

Electrocardiogram data were collected using two standard electrodes, one on each forearm. A Hi Gain V75-01 bioamplifier amplified and filtered the signals. The signals were then sent to a digital input on the computer that detected $\mathrm{R}$ waves and measured interbeat intervals in milliseconds.

Skin conductance levels were measured by a Coulbourn V71-23 isolated skin conductance coupler using an applied constant voltage of $0.5 \mathrm{~V}$ across two standard electrodes. Electrodes were filled with a mixture of physiological saline and Unibase (Fowles et al., 1981) and applied to the hypothenar eminence on the left hand after it was rinsed with tap water. A 12-bit analog-digital converter sampled the skin conductance and facial EMG channels at $10 \mathrm{~Hz}$.

Facial EMG was recorded at the corrugator (i.e., brow) and orbicularis oculi (i.e., under the eye) muscle regions on the left side of the face using sensor placements suggested by Fridlund and Cacioppo (1986). Facial skin was prepared using an alcohol pad and electrode gel. Then miniature Ag-AgCl electrodes filled with Medical Associates electrode gel were applied. EMG signals were amplified (X 50,000) by a Hi Gain V75-01 bioamplifier, using 90-Hz high-pass and 1-kHz low-pass filters. The signals were rectified and integrated by a Coulbourn multifunction V76-23 integrator (nominal time constant $=$ $10 \mathrm{~ms})$.

Within each type of imagery condition, data for each physiology variable were averaged over 4second epochs, yielding 4 epochs during imagery and 2 epochs during the recovery period. During the imagery and recovery periods, deltas for each 4-second epoch were calculated by subtracting values from the 4-second baseline epoch immediately before the imagery period. This is a standard approach in within-subjects imagery designs (Witvliet et al., 2001; Witvliet \& Vrana, 1995, 2000) because it highlights the impact of the experimental conditions on the physiological measures. Raw scores alone include variance due to movement and habituation, and hence are difficult to interpret in a meaningful way. Subtracting each trial's baseline from that same trial's data functionally controls for this and displays more clearly the contribution of the experimental condition itself on the physiological measures of interest. Note that for ease of communication, we report analyses on the average imagery and recovery period values, but depict the epoch by epoch data in the figures.

${ }^{2}$ For the justice main effect follow-up analyses, all significant pairwise comparisons had an actual alpha level of $p<.001$.

${ }^{3}$ All $p s<.001$ in post-hoc pairwise comparisons testing all possible contrasts. 